\title{
Los nuevos despotismos: imaginando el fin de la democracia*
}

\author{
The New Despotisms: imagining the end of democracy
}

JOHN KEANE

The UnIVERSITY OF Sydney (Australia)

Artículo recibido: 16 marzo 2016

Solicitud de revisión: 08 abril 2016

Artículo aceptado: 19 julio 2016

Resumen

Este ensayo nos proponemos plantear una nueva perspectiva acerca de una tendencia inquietante que está configurando nuestro mundo en estos primeros años del siglo xxI: el auge del despotismo. Nos preguntamos si los regímenes de poder que se ponen de manifiesto en países como Rusia, Vietnam, Arabia Saudita, Turkmenistán, China y Brunei, y los Emiratos Árabes Unidos tienen características en común, a pesar de ser a su vez tan diferentes en otros aspectos. La respuesta es afirmativa; empezando por su concentración geográfica en la región euroasiática, definida ampliamente de tal suerte que incluya el espacio territorial que se extiende a lo largo de Rusia,Turquía, las monarquías del Golfo e Irán en el oeste, atravesando las repúblicas de Asia central, China y Japón, hasta Indonesia, Australia, Nueva Zelanda y Fiji en el extremo este. Esta región es el nuevo centro gravitacional geopolítico del planeta. Este ensayo explica por qué el despotismo, término en desuso, merece ser retomado, y porqué los regímenes despóticos de nuestro tiempo no deben considerarse simplemente como un tipo de estado territorial.

Palabras clave: despotismo, política, democracia, sociedad civil.

\begin{abstract}
This essay sets out to make new sense of a disturbing trend shaping our world in these early years of the $21^{\text {st }}$ century: the rise of despotism. It asks whether the regimes of power displayed in countries otherwise as different as Russia, Vietnam, Iran; Saudi Arabia; Turkmenistan; China and Brunei, Saudi Arabia and the United Arab Emirates share things in common. It answers that they do, beginning with their geographic concentration in the Eurasian region, broadly defined to include the territorial spaces stretching from Russia, Turkey, the Gulf states and Iran in the west through to the central Asian republics, China and Japan, Indonesia, Australia, New Zealand and Fiji in the far east. The region is the new
\end{abstract}

*Artículo traducido por Cristian A. Osal López, Universidad Católica Andrés Bello (Venezuela). 
geo-political centre of gravity of our planet. It is also the heartland of the new despotisms, which are proving to be powerful actors, both in the region and within a wide range of global settings. The essay explains why the old-fashioned term despotism deserves to be revived, and why the new despotisms of our time should not be thought of simply as a type of territorial state.

Keywords: despotism, politics, democracy, civil society.

\section{INTRODUCCIÓN}

Este ensayo se propone plantear una nueva perspectiva acerca de una tendencia inquietante que está configurando nuestro mundo en estos primeros años del siglo xxi: el auge del despotismo. Nos preguntamos si los regímenes de poder que se ponen de manifiesto en países como Rusia, Vietnam, Arabia Saudita, Turkmenistán, China y Brunei, y los Emiratos Árabes Unidos tienen características en común, a pesar de ser a su vez tan diferentes en otros aspectos. La respuesta es afirmativa; empezando por su concentración geográfica en la región euroasiática, definida ampliamente de tal suerte que incluya el espacio territorial que se extiende a lo largo de Rusia,Turquía, las monarquías del Golfo e Irán en el oeste, atravesando las repúblicas de Asia central, China y Japón, hasta Indonesia, Australia, Nueva Zelanda y Fiji en el extremo este. Más de un observador señala que los lineamientos básicos del orden global del futuro están siendo forjados actualmente en esta región. Allí se concentra el grueso de la población mundial, y durante la actual crisis del Atlántico ha superado en inversión, producción y exportación a los demás países del mundo: es el nuevo centro gravitacional geopolítico del planeta. Y es también el corazón de los nuevos gobiernos despóticos, que están demostrando ser actores poderosos tanto en dicha región como en gran parte de la configuración global. Este ensayo explica por qué el despotismo, término en desuso, merece ser retomado, y porqué los regímenes despóticos de nuestro tiempo no deben considerarse simplemente como un tipo de estado territorial.

Los nuevos despotismos, además de involucrarse en proyectos empresariales conjuntos y en diversas entidades jurídicas, se entrelazan por medio de varios organismos regionales y por ende sus efectos tienen un alcance que va mucho más allá de sus fronteras: en Asia Central, los regímenes despóticos están configurados por negocios y pandillas armadas que operan por fuera de la Rusia de Putín, y sus bazares están repletos de productos chinos; en Egipto, a partir del golpe de estado en 2013, Arabia Saudita, Los Emiratos Árabes Unidos y Kuwait han invertido aproximadamente 12 
mil millones de dólares (Georgy, 2015); a principios de 2014, los gobiernos de Omán e Irán finalizaron un acuerdo para construir un gasoducto de mil millones de dólares, para proveer a Omán de gas iraní por veinticinco años (Al Hasani, 2014); y para dar un último ejemplo, mientras que el régimen de Omán ha rehusado unirse políticamente con otras monarquías del Golfo, ha apoyado la creación de una alianza de seguridad de protección mutua en caso de que surjan problemas, tal como ocurrió en Barein en 2011, cuando tropas de Arabia Saudita rescataron al régimen del colapso. El despotismo es un fenómeno con potencial regional y global.

\section{LOS PUEBLOS SOBERANOS}

Además de la concentración geográfica, ¿estos regímenes tienen alguna otra característica en común? En este ensayo se arguye que sí.

La característica más sobresaliente a primera vista es la manera como los oficialistas, desde la cima hasta la base del sistema político, emplean regularmente la retórica de la democracia y se refieren constantemente a la supuesta fuente de autoridad soberana: «el pueblo». Los déspotas más astutos saben que si bien es importante tener al servicio secreto, periodistas y censores de su lado, también deben pagar tributo -al menos en apariencia- al principio fundamental de que la autoridad de las instituciones de un país proviene del apoyo del pueblo. Estos nuevos gobiernos déspotas nutren su propia autoridad pública a través de medios impregnados de un fuerte sentimiento "democrático». Trabajan duramente para asegurar que millones de personas reconozcan incuestionablemente que la obediencia a sus dictámenes es justa y apropiada, y que todas las instituciones del sistema de gobierno son la materialización de su poder colectivo.

Es como si en estos nuevos despotismos existiera un pacto silencioso, no escrito o tácito entre las autoridades gobernantes y la población. Su clave operativa parece ser «nosotros gobernamos y les brindamos cosas a cambio de vuestra lealtad pacífica». Esta es una diferencia fundamental con los regímenes totalitarios del siglo xx. Lejos han quedado aquellos días cuando millones de personas en masa, ebullicientes y amontonadas, eran cautivadas por las actuaciones de un periódico, radio o película hábilmente orquestada, protagonizada por los demagogos de la farándula que, según el caso, vestían traje de etiqueta, uniforme militar, o atuendo recio de macho, el torso desnudo, ayudando a los sudorosos trabajadores a cosechar -la especialidad de Mussolini.Ya no celebran millones de personas marchando al unísono frente 
a un escenario construido a partir de la glorificación de héroes, del culto a los caídos, de los feriados nacionales, de los aniversarios, de los triunfos de la revolución y de las actuaciones deslumbrantes del líder. Los nuevos despotismos hacen un profuso uso retórico del «pueblo» pero no requieren del culto político ni de luchas por el reconocimiento y la liberación del mismo. Se espera que los ciudadanos singulares, reales, estén tranquilos, encerrados en sus círculos de trabajo, de vida familiar, de consumo y otras formas privadas de auto-indulgencia o celebración. Se espera que la gente sea diligente y que vean que la política no les concierne.

Esta fórmula permite que prácticamente todo lo hecho por los gobernantes se haga en nombre del pueblo, al punto de rayar en lo hipócrita o tragicómico. Al reflexionar sobre el caso de la República Popular de China [People's Republic of China], Yu Hua en su libro China en diez palabras, resalta que en el idioma chino moderno no hay una expresión que sea tan anómala como la del «pueblo», caracterizado como ubicuo y a la vez invisible. Ese es un punto importante: el despotismo prospera sobre representaciones del «pueblo» como un fantasma viviente. En el imaginario del despotismo, la gente son seres, y no-seres, con suprema importancia política, y sin importancia alguna.

\section{RELACIONES PATROCINADOR-CLIENTE}

Envueltos en esta farsa del pueblo soberano, los despotismos contemporáneos son sistemas de gobierno guanxi. Con esto me refiero a que estos nuevos gobiernos despóticos conforman redes de conexiones y acuerdos que atraviesan desde lo más alto hasta la base y de lado a lado las estructuras institucionalizadas de poder. Los nuevos despotismos ponen en tela de juicio la conocida tesis de que el clientelismo es un vestigio del subdesarrollo, una forma de corrupción «tradicional» que la modernización política reducirá o erradicará. Los nuevos despotismos demuestran lo contrario: resaltan la duración de sistemas de clientelismo mayoritariamente invisibles pero pujantes, los cuales aseguran que bienes, favores, servicios y especialmente dinero sean intercambiados por el apoyo político anidado en los acuerdos de poder que hacen al sistema en su conjunto.

El despotismo por naturaleza alimenta a la corrupción. La corrupción por naturaleza nutre al despotismo. Lograr que las cosas se hagan, generalmente implica pagarle a todos los que importan: esto es a muchísimas personas, incluyendo amigos, vecinos y conocidos, periodistas, burócratas, legisladores, 
jueces, encuestadores, celebridades y hombres de negocio. Dentro y alrededor de estos círculos, las oportunidades y los resultados se distribuyen desigualmente. El despotismo es un poder estructurado por clientes y patrocinadores interconectados, organizado jerárquica y verticalmente. La regla básica del juego parece ser abiertamente «democrática»: entre nosotros intercambiamos esto y los dos tomamos aquello, de modo que cada uno de nosotros se beneficia de dar esto y recibir aquello. Sin embargo, en condiciones de despotismo, es bien sabido que todo se inclina a favor del más poderoso. Las relaciones patrocinador-cliente no son solamente relaciones de intercambio mutuamente beneficiosas sino asimetrías de poder. Los nuevos despotismos cultivan el acceso selectivo a los recursos clave, ya sean oportunidades educativas, prestigio, trabajo, dinero, fábricas o armas.Aquellos que tienen acceso a la red enmarañada de patrocinadores, subpatrocinadores, e intermediarios, requieren y en última instancia dependen de la subordinación de sus clientes. En un régimen despótico, son muchos los que pierden.

\section{PLUTOCRACIA}

Los despotismos de nuestro tiempo son una mezcla de acuerdos políticos y concentración de capital privado. Se ciñen al principio fundamental de Deng Xiaoping: «Dejemos que algunas personas se hagan ricas primero», y así crean grandes fortunas. En estos sistemas, como indica el manual, los mercados difícilmente son «libres» $\mathrm{o}$ "competitivos», la riqueza y los patrones de ingreso son altamente sesgados, los coeficientes de Gini son altos. Daniel Kimmage ha apodado a la Rusia de Putín como una "cleptocracia», una forma de gobierno basada en la riqueza impulsada por el deseo de adquirir ganancias materiales (2008). El neologismo captura la esencia de una tendencia más extendida, ya que subraya el modo como los nuevos déspotas se dedican ante todo a manipular la maquinaria del estado para atender los intereses de negocios privados.

Desde la jerarquía sólo hay discursos positivos. Los regímenes despóticos vienen disfrazados de ideologías que predican el interés nacional y la solidaridad nacional; la ley, el orden y la protección frente a «enemigos extranjeros»; la inspiración divina y alusiones a subir la escalera de Jacob hacia el cielo; charlas de anti-imperialismo o movilización étnica; la creación de un nuevo orden político por medio de la revolución, y muestras de benevolencia y «servicio al pueblo». En China, existen frases claves como «socialismo», «sociedad armoniosa», «antigua civilización china», el «sueño 
chino»y otras expresiones demagógicas sobre «el pueblo»y «la democracia». La ventaja táctica de este tipo de gobierno polisémico es que la oposición no necesita ser aplastada en principio. El objetivo político de los gobernantes es más bien meterse en la cabeza de sus opositores, explotarlos y hacerlos ver como tontos. La estrategia diseñada por el Vladislav Surkov de Putín sirve de ejemplo: en un momento habría financiamiento para foros cívicos y las organizaciones no gubernamentales de derechos humanos, y al día siguiente se financiaba a los movimientos nacionalistas que consideraban a estas organizaciones no gubernamentales como herramientas del Oeste; entonces apoyaban lujosos festivales de arte de artistas de Moscú, modernos y provocativos, para luego apoyar a fundamentalistas ortodoxos vestidos de negro y cargando cruces, quienes procedían a atacar al arte moderno tildándolo de decadente. "La idea del Kremlin», escribe Peter Pomerantsev,

es adueñarse de todas las formas de discurso político, no permitir que ningún movimiento independiente se desarrolle fuera de sus paredes. Su Moscú puede sentirse como una oligarquía por la mañana y una democracia por la tarde, una monarquía a la hora de la cena y un estado totalitario antes de ir a dormir (2014).

\section{CLASES MEDIAS}

Los regímenes despóticos más estables son los que tienen el apoyo político de la clase media. Los nuevos despotismos se especializan en promover el aburguesamiento y a menudo tienen efecto más allá de sus fronteras. Asentadas en ciudades interconectadas como Guangzhou, Shanghai, Singapur, Bandar Seri Begawan, Moscú, Budapest, Ciudad Ho Chi Minh y Dubai, las cadenas de interdependencia de la clase media están fuertemente concentradas en la región de Asia y el Pacífico. Un informe de la ocDE predice que el tamaño de la clase media global aumentará de 1.8 a 3.2 mil millones de personas para el 2020 y a 4.9 mil de millones para el 2030. Se espera que la mayor parte del crecimiento -85\%- provenga de la región de Asia y el Pacífico, y que se dé la misma tendencia en el crecimiento de poder adquisitivo de esta clase $-80 \%$ - en esta región. El informe predice un aumento pronunciado en la demanda de consumo asiática a expensas de la demanda estadounidense. En el 2000, sólo el 10\% del gasto global de la clase media provino de Asia -excluyendo a Japón. Para el 2040, esta cifra «podría alcanzar el 40\%, y podría continuar en aumento hasta alcanzar casi un 60\% a largo plazo» (Kharas, 2010: 28). 
Una gran cantidad de información sugiere que estas clases medias en expansión e intercomunicadas son políticamente promiscuas. En sus escritos de principios del siglo XIX, el primer analista de la democracia, y uno de los más astutos, Alexis de Tocqueville, temía el advenimiento de una forma de despotismo peculiarmente moderna, respaldada por una burguesía con su individualismo narcisista y su materialismo de vivir al día; una clase -como él lo dice- «constantemente rondada por placeres triviales» (1969: 691), un estrato de supuestos ciudadanos dispuestos a adoptar un «poder protector inmenso» que trata a los sujetos como «niños eternos», «como un rebaño de animales tímidos» que necesitan a un pastor. Una lección del despotismo de nuestro tiempo -con el debido respeto hacia Aristóteles, Barrington Moore Jr, Lipset and Fukuyama- es que la clase media no tiene una afinidad unívoca con una democracia que comparte el poder. En más de un caso, en especial cuando los pobres se convierten en engreídos, la clase media muestra síntomas de lo que podría llamarse neurastenia política: lasitud, fatiga, dolores de cabeza e irritabilidad general respecto del desorden social y político. En los países petroleros como Arabia Saudita, Brunei, Kuwait y los Emiratos Árabes Unidos, las clases medias, guiadas por el miedo, la codicia, el honor familiar, profesional y la respetabilidad, parecen contentas de estar cooptadas o secuestradas por los gobernantes del estado, dispuestas a ser compradas con servicios de lujo, pagos en efectivo y beneficios invisibles. Tal es el caso de Rusia; y puede a llegar a serlo en China, donde una de las principales preguntas políticas de nuestra era es si las clases medias en expansión optarán por un régimen estable a cambio de «un estado descentralizado depredador» (Pei, 2006) que les garantice el beneficiarse del crecimiento y hacerse ricos rápidamente.

\section{PSEFOCRACIA}

Los regímenes despóticos convocan elecciones periódicas, al punto de que su profunda dependencia funcional de las mismas y de la victoria electoral les da la apariencia de una psefocracia (Nandy, 2008). Regímenes previos anti democráticos, por ejemplo en Sudamérica, utilizaron las elecciones; pero los despotismos actuales lo hacen de otro modo, de maneras más astutas. De Bielorrusia a Azerbaiyán, Irán y Singapur, los regímenes despóticos adoptan la fachada institucional de democracia electoral a través de la universalización de las franquicias -excepto en Brunei, Arabia Saudita y los Emiratos Árabes Unidos. Les ofrecen a -algunos- candidatos 
la oportunidad de obtener cargos más altos, someten a confirmación electoral al jefe de gobierno, y permiten cierto grado de competencia multipartidista. Los regímenes despóticos también han perfeccionado las artes de la manipulación: excluyen a los candidatos que consideran indeseables, compran votos e intimidan a los votantes, inventan acontecimientos mediáticos sensacionalistas, «manosean» las listas electorales y cuentan erróneamente o hacen desaparecer boletas electorales.

¿Por qué los despotismos se molestan en realizar semejantes prácticas? Es un error suponer que los gobernantes despóticos están desconectados de la realidad, o viven en un estado permanente de negación, o que las elecciones que convocan son meramente referendos propagandistas maquillados. Las elecciones son instrumentos mucho más útiles al gobierno despótico: les brindan a los disidentes dentro de la jerarquía gubernamental cierto espacio para maniobrar. Las contiendas electorales pueden ayudar a saldar viejas cuentas, resolver conflictos y ofrecer opciones de salida de bajo costo a los políticos descontentos del régimen. Las elecciones pueden crear oportunidades para descubrir nuevos talentos -cómplices de poder, en ciernes-, distribuir patrocinios a -potenciales- partidarios y para hacer una detección temprana de focos de desafección y oposición. Las elecciones pueden ser poderosos medios para poner a los partidos opositores en aprietos: sus fracasos, casi indefectibles, implican desmoralización y parálisis. Las mismas también tienen como efecto el reforzar la legitimidad de quienes gobiernan desde lo alto del poder. Las elecciones, como farsa, son una celebración impresionante del tremendo poder del régimen. Pueden incluso llegar a ofrecerle a los sujetos la oportunidad de comportarse como si creyeran en el régimen, por medio de un «contrato electoral».

\section{EL CULTIVO DE LA APARIENCIA POR PARTE DE LOS MEDIOS}

En condiciones de despotismo, los poderosos nunca deben ser descubiertos y expuestos «al desnudo». Son habituales los «secretos a voces»: cosas que la mayoría de la gente sabe y difunde a través del chisme y por lo bajo, aunque todo se cubra con una cortina de apariencias. Hay mucho simulacro por parte de los medios, y se cultiva el arte de la simulación. Todos saben que el principio WYSIWYG -del inglés, lo que ves es lo que obtienes- no se aplica en estos casos. Lo que ven, oyen o leen, no es lo que obtienen. Los sabios del despotismo son por lo tanto personas que cultivan el arte de interpretar los discursos en código, o lo que los italianos llaman 
dietrologia, o "trasdología»-behindology en inglés-, el arte de decodificar explicaciones superficiales u oficiales para entender lo que hay detrás o dietro.

El arte de la sospecha y de ver lo que hay detrás de las apariencias se aprende con dificultad, en parte porque generalmente el «quien es quién» y el «que es qué» está en perpetuo movimiento. Los regímenes despóticos pueden parecer infranqueablemente estables, pero el exceso en el aparentar significa que para muchos la viva realidad es una profunda incertidumbre. Nada es lo que parece. Nada es verdadero, todo es posible, especialmente si se puede pagar por ello, tal como lo enfatiza Peter Pomerantsev al analizar el nuevo mundo de espejos de la Rusia de Putín (2014). Si las cosas sólo estuvieran al revés, los individuos que intentan decodificar el mundo del poder simplemente deberían pararse de cabeza. Con un poco de práctica se convertirían en maestros; pero su desdicha es que las cosas nunca están simplemente invertidas.

El sospechar y el ver a través de las apariencias es un arte difícil de aprender, también porque los nuevos despotismos más sofisticados se esmeran por ser atractivos, o así se lo proponen. Los historiadores nos cuentan que los déspotas del imperio bizantino se vestían con perlas de colores púrpura y blanco. Los nuevos déspotas visten marcas de alta costura. La televisión, la radio y la prensa escrita se usan como medios de actuación política. Así también el Internet, cuyos flujos de información no son simplemente censurados; en su lugar, los despotismos más inteligentes tratan a la comunicación en línea de los ciudadanos como un sistema de alerta temprana, incluso como una válvula de vapor virtual para ventilar agravios a su favor. Lo hacen utilizando técnicas tan sofisticadas como programas de «extracción masiva de datos», «centros de situación» que vigilan los signos de fermentación de malestar o protestas públicas, departamentos para la «refutación de rumores» y experimentos con «polemistas de Internet»contratados. Los gobernantes también construyen oficinas virtuales de peticiones, «chats» organizados entre autoridades y ciudadanos, foros abiertos en línea donde los ciudadanos pueden exponer quejas para ver y oír como las manejan los oficiales. Todo esto ocurre gracias al rol pivote que juegan las empresas con licencia de Internet; que a su vez están obligadas por constantes recordatorios de que las válvulas de seguridad pueden transformarse en artefactos explosivos, de allí la necesidad de utilizar técnicas de filtrado para eliminar o modificar el contenido «delicado».

Los regímenes despóticos son mediocracias organizadas: los medios corporativos, el periodismo, la prensa y el gobierno se combinan y fusio- 
nan. Este devaneo cumple múltiples funciones. La eficacia de los gobiernos y de sus métodos de vigilancia requiere un acceso seguro a las infraestructuras de comunicación. Las grandes empresas de comunicación generan empleos y -en ocasiones-ingresos fiscales. Tampoco se debe subestimar el papel que juegan, fortaleciendo a los gobiernos con la fuerza de una poderosa cobertura mediática positiva, o manejando a la oposición con cruzadas de intimidación, difamaciones, listas negras, asesinatos de personajes y otros tipos de tratamiento mediático corrupto. Entretanto, las grandes empresas de comunicación dependen de los marcos regulatorios de protección establecidos por los gobiernos déspotas. Les gustan las exenciones fiscales, los refugios financieros, los parques empresariales y los folletos en forma de contratos con el gobierno.

\section{LA EFICACIA DE LA VIOLENCIA}

Los nuevos regímenes despóticos son también estados policiales, aunque tienen una diferencia. Estos regímenes muestran gran determinación a la hora de suprimir los primeros signos de disidencia, pública o privada.

En Bielorrusia, el presidente Lukashenko arremete contra la «democracia sin sentido», mientras que sus agentes de la KGB -cómo todavía los llaman en el país- golpean a sus oponentes hasta dejarlos «sin sentido». En Kazajstán, se ha sabido que a los trabajadores de derechos humanos a menudo se les talla una gran X -la marca de la censura- sobre la piel en su torso desnudo. La policía religiosa del régimen saudí, los mutaween, respaldada por la costumbre de decapitar públicamente a opositores, se especializa en difundir el miedo a diferentes sectores de la población. A Putin le gusta citar a Alejandro III, diciendo que Rusia tiene sólo dos aliados, su ejército y su marina; en un reciente discurso sobre la anexión de Crimea (2014), enfatizó particularmente los peligros que plantea una «quinta columna» $\mathrm{y}$ «traidores nacionales» que trabajan para bloquear el avance de la madre patria. Entonces, sus tecnólogos políticos, sus «flautistas», sus agentes de relaciones públicas, y sus magos mediáticos -uno de los más conocidos es Vladislav Surkov, apañador, novelista y fanático del gangsta raprepiten el mantra conmovedor: el presidente Putin es el presidente de la «estabilidad», el remedio de torso desnudo, montado en un oso, para la pasada era de «ocaso y confusión», «el gerente eficiente» que está rehaciendo a la gran Rusia y que tendrá cero tolerancia con los «enemigos de la estabilidad». 
Respaldado por tales mantras, ciertamente hay momentos en los que toda la maquinaria del estado se moviliza en contra de los opositores de turno. La violencia, con toda su fuerza cae duramente, como en la represión violenta de Uigures en Xinjiang en la China del oeste, o la brutal supresión de la Hermandad Musulmana en Egipto, o cuando, durante los juegos olímpicos de invierno en Sochi, los manifestantes fueron recibidos con gases lacrimógenos, latigazos y con la policía antidisturbios fuertemente armada, junto a soldados y agentes del Servicio Federal de Seguridad del Ministerio del Interior. El potencial de este completo despliegue de violencia significa que el miedo es un fruto venenoso del nuevo despotismo.

Los regímenes despóticos pueden ser brutales; su violencia desenfrenada puede ser repugnante; el ejército, la policía y los matones están al acecho constante. Pero es digno de destacar que el modo en que usan la violencia concentrada es normalmente con mesura, a menudo externalizada y -hasta el momento en que golpea- considerada un asunto sombrío. Los déspotas conocen la famosa máxima de Mao Zedong (1975: 224), que el poder político nace del cañón de un arma de fuego, pero están igualmente al tanto de que el despliegue de fuerza sin restricciones, o imprudente, alberga riesgos. Los gobernantes despóticos sienten que, cuando todo está dicho y hecho, se necesita muy poco para apuntalar el orden político, a excepción de la creencia de la gente en el mismo. Potestas in populo fue la formulación romana clásica. En el capítulo 5 del best-seller Los derechos del bombre, Thomas Paine afirma que: «La fuerza y el poder del despotismo consiste enteramente en el temor a resistirse al mismo» (1791: 164). La versión china contemporánea podría ser: el agua en la que flotan los barcos también puede volcarlos. Así que si el poder de un régimen es su capacidad para hacer que sus súbditos actúen a su antojo, la violencia es en última instancia un recurso limitado.

Las órdenes y la obediencia resultan ser elementos engañosos en cualquier ecuación política, ya que el poder sobre otros requiere que se sientan cómodos con las instrucciones, directivas y órdenes emitidas por quienes gobiernan. Los gobernados tienen que estar en silencio o abiertamente convencidos de que no van a ser devorados por las fauces del poder. Esta es la razón principal por la que los despotismos optan por la violencia eficiente, esto es, comedida y camuflada. El caso de Rusia no es del todo atípico. Los métodos utilizados por sus gobernantes pueden ser a veces burdos -derramar veneno radiactivo en el té-, pero la mayor parte de los hechos violentos políticos no se realizan a través el gobierno central, sino por medio de jefes políticos locales, del servicio secreto, o directamente 
por matones o miembros del crimen organizado. El efecto «invisibilidad»se parece más a la externalización de medios de seguridad privada y la violencia en las democracias en efecto existentes, ya que, por ejemplo, en la Unión Europea, por sí sola, más de un millón de personas están empleadas en la policía privada y en los servicios de seguridad.

\section{EL ESTADO DE DERECHO}

Los gobiernos despóticos tienen típicamente constituciones finas, y hay mucho alarde sobre la llegada de la paz al país como fruto de la aplicación del orden a través de la ley -«dictadura de la ley» como lo llama el doble discurso del Kremlin; o «legalización» y «gobierno de la nación según la ley», que es el equivalente de Beijing. Pero la realidad es que bajo un gobierno despótico la ley nunca es simplemente la ley. Los gobiernos despóticos son, de hecho, sistemas de anarquía organizada. «El estado de derecho» significa «imperio de la ley».

De arriba a abajo, la política en condiciones despóticas se asemeja a un "golpe de estado permanente», una evisceración constante de los preceptos constitucionales y los procedimientos del estado de derecho. Si por estado de derecho nos referimos a los códigos de la ley que tienen el efecto práctico de frenar y equilibrar las ambiciones de ambos, los poderosos y los débiles, y de todos los demás que se encuentra en el medio, entonces el despotismo es lo opuesto. Su sistema de leyes impone pocas o nulas restricciones sobre los brutos y matones potenciales. Algunos están por encima de la ley, o escapan de la mano de las leyes publicadas y accesibles al público. Las leyes pueden estar claramente establecidas, pero rara vez se cumplen.

Vamos a explorar sólo un ejemplo, extraído de China, de la forma en que el poder judicial es cómplice del poder arbitrario. Aunque la mayoría de la gente en China nunca ha visto partidos de golf, excepto en las pantallas de televisión, ya están disponibles cursos para los «principitos» y otros ciudadanos chinos adinerados. Durante la era de Mao, este deporte fue prohibido. Apodado «el opio verde», fue denunciado como un pasatiempo burgués frívolo, de los expatriados, un «deporte para millonarios». Durante las reformas de Deng Xiaoping, la posición oficial se invirtió. Pero en 2004, después de muchas olas de protestas locales contra la adquisición obligatoria de tierras, el gobierno central de Beijing legalmente prohibió la construcción de campos de golf. Durante los cinco años siguientes, las cosas rápidamen- 
te cambiaron su rumbo: unos cuatrocientos fairways fueron construidos, incluyendo Mission Hills en Shenzhen, el centro de golf y de esparcimiento mejor calificado de China -o al menos así se ufanan de ello- y club de golf más grande del mundo -donde se realizan un docena de cursos de campeonato-, anfitrión de los torneos más importantes de la región. En otros lugares, con políticas más acordes a la legalidad, tales establecimientos no podrían haber sido construidos, debido a la acción legal de los tribunales. Pero en China, los gobiernos locales, trabajando mano a mano con los desarrolladores y la policía, pisotearon a los agricultores locales, confiscaron sus tierras por casi nada, desafiando al estado de derecho, de conformidad con el principio de poder que establece que ya que la montaña es alta y el emperador está lejos, los mandatos legales de arriba pueden ser fácilmente neutralizados desde abajo. Por supuesto, a cambio de una buena ganancia, para desarrolladores y funcionarios del gobierno local por igual.

No se necesitan tanques o vehículos blindados para alimentar este tipo de anarquía. A través de una combinación de relaciones patrocinadorcliente, sobornos, promociones y despidos, y algún secuestro o asesinato ocasional, los profesionales del derecho y los tribunales están subordinados a los poderes políticos reinantes. También lo están los parlamentos: los gobiernos despóticos debilitan las legislaturas, y las legislaturas débiles fortalecen al despotismo. Toda esta dinámica permite a los regímenes despóticos tratar duramente a sus oponentes. Cargos falsos, desapariciones, detenciones y condenas de los ciudadanos son comunes, a veces hasta el punto de que la mala conducta de la policía y los funcionarios judiciales parece indistinguible de la de los ladrones y criminales.

\section{IMPLICACIONES}

Uno de los objetivos principales de este ensayo ha sido alimentar la capacidad de asombro de los lectores, para inducir perplejidad ante la miríada de hechos novedosos y contradictorios que están ocurriendo en el mundo del poder arbitrario del siglo xxi. Todo este enfoque reconoce la importancia de prestar atención al lenguaje cuando se analiza el poder, así como la dificultad de elaborar definiciones plausibles. La visión de Nietzsche de que sólo las cosas sin antecedentes pueden ser definidas con precisión sin duda se aplica a los regímenes de poder que aparecen en contextos de otro modo tan diferentes como Bielorrusia, Rusia, China, Brunei, Arabia Saudita y los Emiratos Árabes Unidos. 
Al presentar un análisis nuevo de su compleja anatomía, este ensayo ha tenido en advertencia las mentes cerradas. Es, por tanto, una invitación a admitir las incertidumbres, a explorar nuestra propia ignorancia, sobre todo, a ver que los regímenes despóticos contemporáneos no son una realidad simple o sencilla, sino un caldero de tendencias confusas y conflictivas. Estos regímenes no son «democracias defectuosas» o «democracias delegativas» (O'Donnell, 2004) que carecen de controles y equilibrios -checks and balances-, o «democracias no liberales» (Zakaria, 1997) que no logran mantener el estado de derecho. No están en el medio, como los «regímenes híbridos» (Diamond, 2002), las «semi-democracias», los «regímenes semi-autoritarios» o «semi-dictaduras». Son otra cosa, algo novedoso. Estos regímenes son una nueva «realidad» que debe hacernos sentir, en materia de análisis político, la verdad del dicho de que todos nosotros nos parecemos al ciego palpando las diferentes partes de un elefante que no puede ser resumido en términos de un simple libro de texto.

Sin duda, estamos frente a casos políticos que nos interpelan lo suficiente para repensar el viejo término despotismo. Por ejemplo, es tentador, pero engañoso, pensar en el despotismo como una forma política imprudentemente violenta. Montesquieu comentó abiertamente en De l'esprit des lois que bajo un régimen déspota, la desconfianza mutua y el miedo son rampantes. Nadie está a salvo. Las vidas, las libertades y las propiedades de los sujetos están siempre en el aire y a merced de la espantosa máxima «que una sola persona debe gobernar de acuerdo a su propia voluntad y capricho» (1873:22). Los despotismos del siglo xxi no son así. No son repeticiones del totalitarismo de Corea del Norte, por decir algo, o de Camboya durante la década de los años 70, cuando la camarilla gobernante conocida como Angkar -la organización-, en su mayor parte invisible pero igualmente todopoderosa, perfeccionó el radicalismo homicida al punto de causar la muerte de 1,7 millones de personas aproximadamente, una quinta parte de la población del país, por vía de la ejecución, el hambre, la enfermedad, o la descorazonamiento. Los nuevos despotismos funcionan de manera diferente, de modo más sutil, más eficiente, con mucha mayor durabilidad. Sin duda, los acontecimientos de los últimos años en Egipto y Crimea, al igual que los acontecimientos en Xinjiang y el Tíbet, deben servir como advertencia de la devastación que el despotismo puede traer y trae al mundo.

También es claro que el poder a veces nubla el entendimiento a quienes gobiernan, conducen y gestionan los nuevos despotismos. Hay incluso momentos cuando pareciera que han pasado a través de un espejo hacia un 
extraño mundo de ovejas que gritan y flores que hablan, con reinas blancas y reyes rojos, liebres y sombrereros... Putin es propenso a comportarse como un personaje de Las almas muertas de Gogol, una novela que explora la fantasía del estado de poder total y la grandeza mesiánica. En la misma semana en que el mariscal de campo Abdel Fattah al-Sisi anunció que renunciaba a su rol de líder militar para lanzarse a la presidencia, para salvar a su país, 500 miembros de la Hermandad Musulmana fueron condenados a muerte en un día (Guerin, 2014), en un juicio arreglado presidido por el juez Saeed Elgazar -cuyo apellido significa «el carnicero». También hay figuras surrealistas como Saparmurat Niyazov, el déspota de Turkmenistán, elegido para la presidencia con el 98,3\% de los votos, quien fue haciéndose gradualmente más poderoso: Se declaró a sí mismo profeta de Dios en la Tierra (Blua, 2005), e hizo estampar su rostro en billetes, monedas y sellos; ordenaba regularmente a sus ministros realizar caminatas de 5 millas, prohibió el ballet, la ópera y los cines (Halpin, 2008), erradicó los perros de Ashgabat a causa de su «olor desagradable» (Hiro, 2009: 227), y publicó una guía de 400 páginas para el pueblo de Turkmenistán (BBC News, 2001) -el Rubnama, cuyos pasajes fueron pegados en las paredes de la mezquita. También cambió el nombre de los meses del año -septiembre se convirtió en Ruhnama, el mes en que Niyazov terminó de escribir su obra magna (Harding, 2008)- y prohibió escuchar las radios de coche, que, según él, se usaban para camuflar charlas subversivas de los ciudadanos. Cuando una serie de pronósticos del tiempo resultó poco fiable, despidió personalmente a los principales meteorólogos del país (Pannier, 2001).

Es fácil reírse de estos absurdos de poder ilimitado. Pero es preocupante el hecho de que algunos de los nuevos despotismos presenten signos de estar convirtiéndose en regímenes despóticos altamente resilentes e «iluminados». No sólo se alimentan hábilmente de las disfunciones de las democracias existentes o en transición, y paradójicamente se burlan de sus debilidades e imitan sus mejores cualidades, sino que proclaman ser más inteligentes, más eficientes y eficaces que las democracias. Especialmente llamativo resulta la ultra modernidad de estos regímenes, su propensión al auto-control y la experimentación con las prácticas «democráticas». La forma en que estos despotismos están aprovechando Internet para controlar Internet -el caso de China es probablemente el más avanzado- debería 
ponernos en guardia, vigilantes, desconfiados del viejo principio de Montesquieu de que los regímenes despóticos cavan sus propias tumbas ${ }^{1}$. El punto clave a este respecto es que los nuevos despotismos sobreviven porque cultivan formas que aseguran que sus súbditos les permitan sobrevivir. Su resistencia está garantizada por la disposición de las personas a conformarse, a no hacer nada para cambiar el régimen y sus rutinas, a criar ojos ciegos y oídos sordos frente a las disfunciones y las injusticias: Los despotismos duraderos son sistemas de servidumbre voluntaria. Convierten a sus súbditos en memes o portadores de ideas, formas de expresión y de prácticas simbólicas, despóticas. El hecho de que estén logrando hacerlo, y además con un poco de finura, debe preocupar a cada mujer y hombre pensante que valore la vida libre del dominio de un poder arbitrario.

\section{BIBLIOGRAFÍA}

Diamond, L. (2002): «ThinkingAbout Hybrid Regimes», Journal of Democracy, 13, pp. 21-35.

Hiro, D. (2009): Inside Central Asia, New York, Overlook Press.

JENSEN, J. (2008): «Civis mundi sum: global civil society», Recerca. Revista de Pensament $i$ Analisi, 8, pp.67-89.

Khara, H. (2010): "The Emerging Middle Class in Development Countries». Working Paper, 285, Paris, OECD Development Centre.

Montesquieu, C. D., \& Nugent, T. (1873): The spirit of laws Vol. I, Cincinnati, Robert Clarke.

O’donnell, G. (2004): «Delegative Democracy», Journal of Democracy, 5, pp. 55-69.

PAINE, T. (1996): Rights of Man, Hertfordshire, Wordsworth Editions.

1 Desde el principio venimos señalando que los despotismos se apoyan en las debilidades de la democracia, sacan partido de ellas, y además experimentan con prácticas «democráticas». Estos regímenes tienen un enorme potencial global, por lo que no deben considerarse como simples estados territoriales: su armazón ya excede la simple estructura de un gobierno estatal. Los sucesos que aquí se mencionan son preocupaciones contemporáneas, y el fenómeno del despotismo no es una preocupación nueva. En este sentido cobran vigencia artículos como el de Jensen (2008) donde se plantea que la sociedad civil emerge como actor a propósito de los conflictos y limitaciones de las democracias, tematizando y problematizando la capacidad que tienen las redes globales de la sociedad civil para afrontar a estos problemas. Si una sociedad civil global, puede hacerse cargo, puede responder de las deficiencias de la democracia, con soluciones alternativas globales, esas mismas estructuras podrían servir para hacer frente a los nuevos despotismos. 
PEI, M. (2006): China's trapped transition: the limits of development autocracy, Cambridge, Harvard Press University.

Tocqueville, A. (1969): Democracy in America, New York, Anchor Books.

ZAKARIA, F. (1997): "The Rise of Illiberal Democracy», Foreign Affairs, 76, pp. 22-43.

ZEDOng, M. (1975): Selected Works of Mao Zedong Vol. 2, Beijing, Foreign Languages Press.

\section{OTRAS FUENTES}

Al Hasani, S. (2014): «Iran says seals gas export deal with Oman», Reuters, consultado el 12 marzo 2016, disponible en http://www.reuters.com/ article/us-iran-oman-gas-idUSBREA2B24K20140312

$B B C$ NEWS (2001): "The cult of the Turkmen leader», consultado el 12 marzo 2016, disponible en http://news.bbc.co.uk/2/hi/asia-pacific/1634100. stm

BluA, A. (2005): "Turkmenistan: Circumstance Of Niyazov's Birthday Surrounded By Plenty Of Pomp", Radio Free Europe Radio Liberty, consultado el 12 marzo 2016, disponible en http://www.rferl.org/content/article/1057515.html

Georgy, M. y Kal, S. (2015): «Gulf Arab allies pledge \$12 billion to Egypt at summit», Reuters, consultado el 12 marzo 2016, disponible en http:// www.reuters.com/article/egypt-economy-investment-IDUsL5NOWF1 LO20150313

Guerin, O. (2014): «Egypt court sentences 528 Morsi supporters to death», BBC News, consultado el 12 marzo 2016, disponible en http://www. bbc.com/news/world-middle-east-26712124

Halpin, T. (2008): "Turkmenistan lifts curtain on banned arts», The Times, consultado el 12 marzo 2016, disponible en http://www.thetimes.co. uk/tto/news/world/asia/article2608210.ece

HARDING, L. (2008): "Turkmenistan to drop late dictator's month names», The Guardian, consultado el 12 marzo 2016, disponible en http:// www.theguardian.com/world/2008/apr/25/1

Kimmage, D. (2008): «Russian 'Hard Power' Changes Balance In Caucasus», Radio Free Europe Radio Liberty, consultado el 12 marzo 2016, disponible en http://www.rferl.org/content/Russia_Changes_Balance_In_ Caucasus/1190395.html 
Nandy, A. (2008): «Democracy Is Now Psephocracy» [Entrevista por Sheela Reddy], Outlook India, consultado el 12 marzo 2016, disponible en http://www.outlookindia.com/magazine/story/democracy-is-nowpsephocracy/237806

Pannier, B. (2001): «Turkmenistan: For Niyazov, Good Government Help Is Hard To Find", Radio Free Europe Radio Liberty, consultado el 12 marzo 2016, disponible en http://www.rferl.org/content/article/1096956. html

Pomerantsev. P. (2014): "The Hidden Author of Putinism», The Atlantic, consultado el 12 marzo 2016, disponible en http://www.theatlantic.com/ international/archive/2014/11/hidden-author-putinism-russia-vladislav-surkov/382489/

Putin, V. (2014): "Address by President of the Russian Federation», Official Internet Resources of the President of Russia, consultado el 12 marzo 2016, disponible en http://en.kremlin.ru/events/president/news/20603 